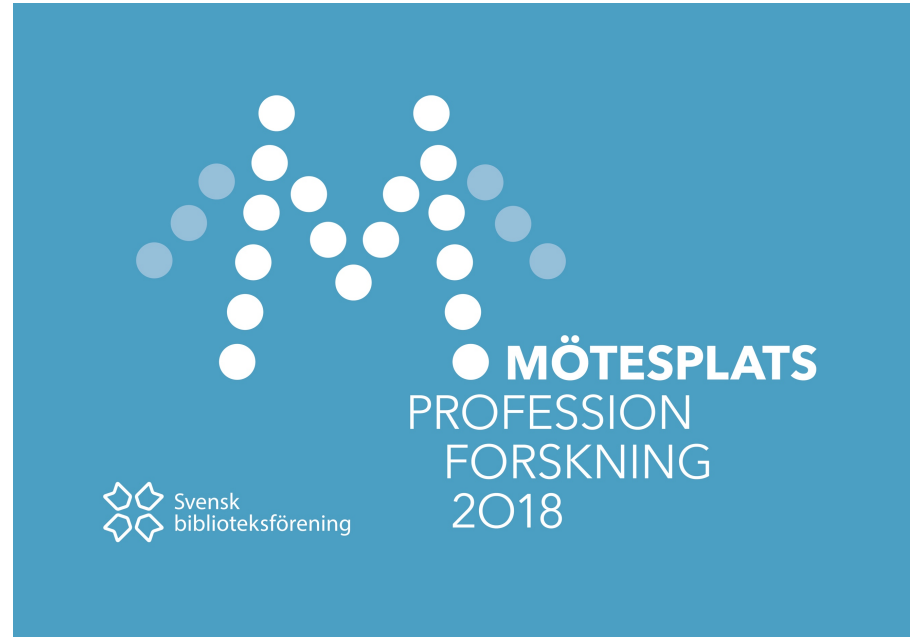

Julia Pennlert

Högskolan i Borås, Bibliotekshögskolan

julia.pennlert@hb.se

\title{
Litteratur genom örat - ett pilotprojekt om ljudbokens potential och begräsningar.
}

\section{Inledning}

Den kommersiella ljudbokens snabba etablering på den svenska bokmarknaden väcker känslor. Under våren 2018 diskuterades den så kallade "ljudbooksboomen" frekvent på Dagens Nyheter. I debatten framhöll journalister, författare och förläggare, från olika perspektiv hur ljudbokens form och format påverkar litteraturen och läsaren. (Pennlert, submitted, 2018). Diskussionen visar också hur förlagen på olika sätt tvingas förhålla sig till ett digitalt mediesamhälle där läsaren anammat digitala läsvanor.

Att läsarna har hittat till ljudboken är även ett samband som de senaste åren rapporter och bransch-statistik på olika sätt betonar. I exempelvis Bokförsäljningsstatstiken - första halvåret 2018 konstaterar rapportförfattaren Erik Wikberg att "digitala abonnemangstjänster står ut från övriga kanaler och visar en ökad försäljning med 36.9\%" samt att "försäljningen av digitala ljudböcker" ökat med 37.2 \% (Wikberg 2018). I samma rapport poängterar även Wikberg följande:

Det är i sammanhanget intressant att noterat att försäljningen av digitala böcker, både e-böcker och digitala ljudböcker minskar kraftigt i internetbokhandlen, som säljer dessa produkter styckvis. Detta tyder på att försäljningen av digitala böcker alltmer koncentreras till digitala abonnemangstjänster. (s.5)

Wikbergs iakttagelser visar alltså flera parallella rörelser som kan sägas rita tidigare vedertagna modeller för textens väg till en läsare men visar också på signifikanta förändringar i läsarens beteende och benägenhet att välja och konsumera ljudböcker via något av de förlag som bygger på en prenumerationsbaserad affärsmodell. I en annan rapport, Boken 2018 - 
Marknaden, trender och analyser, gör samme Wikberg en liknande observation och diskuterar hur dessa nya digitala distributionskanaler potentiellt påverkar förlagsbranschen. Wikberg skriver:

De digitala abonnemangstjänsterna har en annan affärsmodell än andra försäljningskanaler. Istället för att köpa ett exemplar av en bok köps istället rättigheten till att läsa eller lyssna på böcker i digitalt format under en viss tid. I denna kanal ökade det totala antalet lyssnade/lästa digitala böcker med 64,8 procent. Det finns uppenbara skillnader mellan ett köp av en fysisk bok och att läsa eller lyssna på en bok i en digital abonnemangstjänst. Den köpta fysiska boken ägs av personen och kan läsas flera gånger eller inte läsas alls. I digitala abonnemangstjänster mäts konsumtionen av en bok efter hur många gånger den lästs eller lyssnats på. (s. 20)

Genom den digitala kommersiella ljudbokens utveckling finns det alltså fog för att påstå att litteraturläsningen och bokbranschen förändras. I tidigare studier betonas att även om ljudboken utmanar konventionella sätt att se på läsning och läsupplevelse (Rubery,. 2011, p. 1.) är forskning om ljudböcker sällsynt och som vardagligt fenomen är denna typ av litteraturkonsumtion mer eller mindre outforskad. (Have \& Stougaard Pedersen, p.5.) I The untold story of the talking book (2016) poängterar Matthew Rubery att det saknas en "vokabulär" för att utforska och diskutera relationerna mellan den tryckta boken och ljudboken. Rubery skriver följande:

“(...) despite the audiobook's prominence (it stands out as one of the only types of reading that have grown in popularity), we still lack a vocabulary for discussing its relationship to conventional books, not to mention its uncertain standing in the world of letters. (Rubery, 2016 s.1)

\section{Syfte och frågeställningar}

Syftet med denna text är, för att följa Ruberys ovanstående resonemang, att studera på vilket vokabulär som används när ljudbokens form och format diskuteras i ett svenskt pressmaterial. Denna ingång gör det även möjligt för mig att belysa vilken roll ljudboken har i relation till den litterära texten och den läsare som potentiellt konsumerar litteratur i detta format. Formulerat som frågeställningar är ambitionen med denna text att vidare undersöka följande:

- På vilket sätt framställs ljudbokens form och format i debatten?

- Vilken typ av läsare porträtteras i pressmaterialet?

- Vilka potentiella konsekvenser kring läsning i ett digitalt mediesamhälle kan ljudboken sägas innebära?

\section{Boken, läsaren och den digitala tekniken - teoretiska perspektiv.}

I ett generellt perspektiv kan etableringen och användningen av ljudböcker kopplas till frågor som rör den digitala teknikens utveckling och digitaliseringen av den tryckta boken. Denna utveckling innebär, som Bergström \& Höglund (2016) noterar att den digitala samtiden potentiellt leder till att den tryckta boken "ändrar karaktär", samt att bokmarknaden i likhet med musikindustrin och journalistiken måste hantera framväxande digitala kanaler för distribution av innehåll. Bergström och Höglund påpekar följande: 
Det är ännu för tidigt att sia om var bokbranschen kommer att landa, men helt klart förändrar bokens digitalisering bokmarknaden och förlag och bokhandel tvingas bygga en digital strategi.(s.419)

Ett annat perspektiv på hur den digitala tekniken och det faktum att den på sikt påverkar litteraturen och läsaren framhålls även av andra forskare även i en internationell kontext. I exempelvis Words onscreen (2015) argumenterar Naomi S Baron att läsningen som aktivitet $\mathrm{i}$ samtiden kan placeras in i en informations-diskurs, där läsaren i en digital miljö anpassar sig till det faktum att allt fler texter distribueras genom digital teknik.(jfr. Hayles 2012). Baron menar också att detta potentiellt leder till att texten förändras genom att framhålla att den samtida bokmarknaden i en högre utsträckning än tidigare kännetecknas av att prioritera och publicera texter i det kortare formatet (Baron, 2012 s.1). En liknande observation gör Alexandra Borg som placerar läsning i samtiden som en aktivitet som kännetecknas av och tävlar med andra medieformat och medievanor som också påverkar det litterära innehållet (Borg, Tidskrift för litteraturvetenskap, 2013) Borg skriver följande:

Idag när det finns lite utrymme till övers för just läsning, och många nya medier konkurrerar om uppmärksamheten, finns det något tillfredsställande i att bli färdig med det lästa vi har för handen, att få ta del av något litterärt, utan att behöva sätta sig in i en komplex romanhandling. (s. 86-87)

Vad som däremot sker när litteraturen anpassas eller skrivs för att distribueras och konsumeras via ljudboksformatet är sparsamt utforskat. (jfr. Have \& Stougard Pedersen, s. 5, 2016) Ett undantag är Katherine Hayles som i flera studier uppehåller sig vid frågor som rör hur den digitala teknologin påverkar litteraturen och läsaren. Hayles (2007) betonar att viktiga litterära ledtrådar följer med när texten flyttar sig från ett medium till ett annat. Hayles skriver följande

When literature leaps from one medium to another-from orality to writing, from manuscript codex to printed book, from mechanically generated print to electronic textuality-it does not leave behind the accumulated knowledge embedded in genres, poetic conventions, narrative structures, figurative tropes, and so forth. Rather, this knowledge is carried forward into the new medium, typically by trying to replicate the earlier medium's effects within the new medium's specificities. (s. 106)

Med hjälp av Hayles ovanstående resonemang är det möjligt att placera in ljudbokens form och format som en del av medieteoretisk utvecklingslinje, som har gått från "(...) från kassettband till cd-skivor" (Weibull, L \& Nilsson $\AA$, 2010), till att läsaren tecknar en prenumeration på någon av de etablerade ljudboksförlagen och sedan med hjälp av sin mobiltelefon får tillgång till olika litterära texter i varierande genrer och format. Denna historiska parallell drar även Rubery som konstaterar att ljudboken visserligen är en ny form av berättande men har äldre släktingar och historiska motsvarigheter. (Rubery, 2016 s. 6) Även om fokus för denna text inte är att specifikt diskutera det litterära innehållet är resonemangen och reflektionerna från Baron, Borg och Hayles möjliga att applicera även på undersökningen av hur ljudbokens format och vilka effekter den möjligen har på läsningen av litteratur framställs i svenskt pressmaterial. 


\section{Resultat och diskussion}

I debatten som under våren 2018 främst äger rum på Dagens Nyheters kultursida framställs ljudbokens form och format på flera sätt och flera av de medverkande aktörerna; förläggare, författare, kulturjournalister och forskare framhåller sina egna erfarenheter av att läsa eller skriva litteratur förmedlad via ljud. I diskussionen lyfts ljudbokens mediespecifika fördelar - i relation till den tryckta boken - som en litteraturform som lämpar sig väl i en situation när läsaren har händerna upptagna med annat och inte fysiskt kan vända blad eller bläddra sig fram mellan tryckta boksidor. En av ljudbokens fördelar, som den porträtteras i pressmaterialet, är alltså att den gör det möjligt för läsaren att konsumera litteratur när "man kör bil eller promenerar" (Larsson, 2018) och är "lätt att infoga i livspusslet" (Lenas, 2016). Lenas skriver följande:

Om man ändå måste pendla till jobbet varje dag, eller rengöra spisen och vika tvätt en tisdagskväll, är det betydligt lättare att samtidigt lyssna på en ljudbok än att titta på en tv-serie eller läsa en pocketbok. (Lenas, 2016.)

Ljudbokens format och tillgänglighet gör det alltså möjligt för läsaren att ägna sig åt litteraturkonsumtion samtidigt som han eller hon är upptagen med andra aktiviteter och vardagliga bestyr som exempelvis promenader, städning eller matlagning (Sarrimo, 2018). Detta ger också en förklaring till varför ljudbokslyssnandet har ökat, just på grund av att den är lätt att konsumera under tiden som läsaren också ägnar sig åt andra rutinbundna och vardagliga sysslor. (jfr. Ahlström, 2018).

Läsaren som porträtteras i relation till ljudboken kan alltså, med förankring i ovanstående, tolkas som någon som är upptagen med många aktiviteter och vardagliga åtaganden som dagligen ska genomföras och ljudboken som litteraturform är alltså ett läsande som kan möta dessa behov hos läsaren genom just sin möjlighet till mobilitet och flexibilitet. Att läsa en ljudbok är inte en aktivitet som är situerad eller förknippad med en specifik plats (jfr. exempelvis läsfåtöljen, soffan etc.) utan snarare betonar möjligheten för läsaren att befinna sig i rörelse, genom att läsningen går att utföra under promenaden eller i den dagliga morgonpendlingen.

Att samtidens läsare befinner sig mer eller mindre under tidspress noteras också i relation till vilka andra aktiviteter och verksamheter som ljudboken i pressmaterialet jämförs med. Inte sällan görs en koppling mellan digitala ljudböcker och andra strömmande medieformat och tjänster, som exempelvis HBO, eller Netflix. Dessa paralleller visar hur ljudbokens digitala format inte ställs mot bokläsning av en tryckt bok utan istället konkurrerar (ljudboks)läsarens uppmärksamhet med andra medieformer som främst innehåller underhållning, bildmedier och/eller teveserier. I artikeln med rubriken "Sanningen kräver stil och gestaltning" uttrycker författaren Henrik Berggren följande som kan ses som en symptomatisk beskrivning av detta tema i debatten:

Om något hotar bokens framtid är det snarare de nya digitala möjligheterna att skapa och förmedla berättelser i ljud och bild. Här finns de streamade tv-serierna på HBO och Netflix, som på ett fascinerande sätt minner om 1800-talets följetänger i dagstidningarna. (Berggren, 2018) 
En delvis annan hållning intar förläggaren på Ordfronts förlag, Pelle Andersson och uttrycker sig på följande sätt:

Det som just nu händer är en kraftig omvandling av hur vi tillgodogör oss berättelser. Ljudbokens fördel - och förbannelse - att den är det enda formatet där man kan göra något annat samtidigt som du tar till dig berättelsen. Egentligen borde detta vara en revolution och en stor fördel för litteraturen framför det bildburna berättandet.

Andersson och Berggren ger alltså olika nulägesbeskrivningar och förklaringar av litteraturens position och förtjänster $i$ ett digitalt mediesamhälle där många olika medier och berättarformat finns tillgängliga för en läsare - eller kulturkonsument - att välja bland. Berggren framhåller visserligen en historisk utvecklingslinje av följetongen som format men påpekar samtidigt att den digitala medieutvecklingen "hotar bokens framtid." En mindre pessimistisk spaning gör Pelle Andersson som snarare placerar in och tolkar ljudbokens (mobila) format som en "revolution" för den textbaserade litteraturen i relation till mer visuellt, eller "bildburet" berättande.

I diskussionen betonas även på olika sätt hur aktörer, förläggare och bransch, bör förhålla sig till den snabba utvecklingen av ljudboksmarknaden och det faktum att läsarna hittat till de specifika prenumerationsbaserade ljudboksförlag som på senare år etablerat sig på marknaden. Denna utveckling leder till debatt som också kretsar kring hur förlagens digitala prioriteringar ska komma att se ut för att möta utmaningarna som kommer med att läsarna blivit mer benägna att konsumera litteratur i ljudboksformat. I artikeln "Ljudboksboomen skapar konflikt på Bonniers" framhålls och betonas att ljudboken väcker känslor bland förläggares arbetssätt och hur den skönlitterära texten möjligen påverkas av att allt fler läsare lyssnar. I samma artikel betonas även att viss litteratur skulle vara särskilt lämplig för att konsumeras via ljudboksformatet samt att ljudboken kan ses som "det nya massmarknadsformatet" i likhet med pocketbokens historiskt betydelsefulla position på bokmarknaden. Under rubriken "Ljudbokens fördel och förbannelse" påpekar förläggaren på Ordfront förlag, Pelle Andersson att vi befinner oss $\mathrm{i}$ "en kraftig omvandling av hur vi tillgodogör oss berättelser." Andersson skriver:

Vi får en stor grupp människor som bara tillgodogör sig litteratur genom ljudbok - och får en litteratur som är anpassad för den som ska göra något annat men den nya konkurrenssituationen med ett ständigt utbud av underhållning i mobilen gör att förlagen, vare sig vi vill eller inte, måste finnas där med vårt innehåll. Dock tror jag att nya lyssnare, också kan bli nya läsare - och att lyssnarna på sikt kommer att kräva mer avancerade berättelser i lurarna, precis som tv-serieberättandet har utvecklats de senaste åren. (Andersson, 2018)

I ovanstående citat pekar Andersson på flera generella aspekter kring litteraturens position i en digital medievärld och hur förlagen kan hantera en massmedial verklighet där "den nya konkurrenssituationen med ett ständigt utbud av underhållning i mobilen." Anderssons strategi, tycks vara att förlagen "måste finnas" även där läsarna befinner sig. I iakttagelsen finns också en normativ syn på att litteraturen som konsumeras via ljud kommer att bli mer utvecklad och "avancerad" i takt med att denna snabba utveckling saktat in. Det tycks vara så, i enlighet med Andersson, att läsarna kommer att "kräva mer avancerad berättelser i lurarna" 
vilket även ger läsaren en tydlig subjektsposition på bokmarknaden som aktivt styr sina val och som på längre sikt kommer att ändra de redan existerande val som han eller hon gör. Artikeln "Ljudbokens fördel och förbannelse" visar också att ljudboksmarknaden är "ung" samt att förlagen fortfarande "prövar sig fram" kring vilka typ av texter, eller "innehåll" som är lämpligt att distribuera via ljudboksformatet. (Se exempelvis Staffan Wilson, Femina, 19/6, 2018.)

Ett konkret exempel på hur litteraturens form och format påverkas av ljudboken ges av Storytels vd Jonas Tellander och andra förläggare som kommer till tals i pressmaterialet. I artikeln "Så har ljudböckerna förändrat berättandet i dramaturgin" (Ahlström, 2018) konstateras att litteratur som skrivs direkt för att konsumeras i ett ljudboksformatet har särskilda egenskaper och karaktärsdrag, som exempelvis litterära följetonger uppdelade på flera episoder och avsnitt. Även här syns likheten med tv-serier och att det, från förlagens och författarens håll, gäller att producera ett "så bra första avsnitt som möjligt" vilket förläggaren Emma Danielsson på Storytel betonar. Danielsson fortsätter:

Man har inte tid att berätta allt som har hänt fram till nuet, utan lyssnaren får gärna kastas in direkt i berättelsen. Det behövs inte så mycket förförståelse, det ska vara tydligt vad som händer. (Ahlström, 2018)

Hur denna specialskrivna litteratur och strategi potentiellt påverkar litteraturen och läsaren är också föremål för diskussion där kritiker uttrycker en oro för att detta på längre sikt kommer att leda till att andra typer av genrer eller mer "komplex litteratur" kommer att konsumeras i samma utsträckning i framtiden. (Cederskog \& Lenas, 2018) De mer positiva rösterna påpekar istället att kritikerna i högre utsträckning än tidigare måste ta "ljudboken på allvar" (Åberg, 2018). Mittemellan dessa två motpoler, mellan rädslan och realitet, finns de som i debatten påpekar och ger ljudboken legitimitet på bokmarknaden genom att dra historiska paralleller till det muntliga berättandets betydelse för litteraturens utveckling. Författaren Augustin Erba skriver följande under rubriken "Kan du höra den här texten?":

(...) det är uppenbart att ljudboken sluter den orala cirkeln. Förr berättades historierna antagligen medan vi satt instängda i en grotta medan sabeltandade tigrar lurpassade utanför, nu sitter vi oftare i en bil inklämd mellan två långtradare, men även då är det muntliga berättandet svårslaget. (Erba, 2018)

Erba bemöter också de argument som diskuterar hur ljudbokens form och format möjligen potentiellt påverkar litteraturens form och innehåll negativt genom att placera in ljudboken i ett mer generellt perspektiv genom att placera in ljudboksdebatten i ett sammanhang där hur medier påverkar det skrivna ordet tidigare diskuterats och konstaterar följande:

Men, invänder vän av förfluten ordning, hur ska man hantera befintliga böcker? Blir inte litteraturen förflackad av att ljudbokiseras? Denna fråga återkommer regelbundet oavsett om det gäller nya versioner av Pippi Långstrump eller nya mediers uppkomst. Och mitt svar är alltid likadant: det gick att göra nyöversättningar av Bibeln utan att kyrkan gick under, så då är nog fler ljudböcker en hanterbar utveckling. (Erba, 2018)

Syftet med denna text har varit att studera på vilket sätt som ljudbokens form och format porträtteras i den intensiva mediedebatt som främst utspelar sig på Dagens Nyheter under 
våren 2018. Diskussionen visar att det, till skillnad från vad Matthew Rubery observerar $\mathrm{i}$ The untold story of the talking book, finns ett gemensamt språkbruk kring de fördelar och utmaningar som följer med ljudbokens etablering och snabba utveckling på den svenska bokmarknaden. Det som också är slående i debatten är hur ljudbokens format på flera sätt placeras in i ett digitalt mediesamhälle där läsaren kan välja bland flera olika mediala format och digitalt strömmande medietjänster. Hur detta i förlängningen kommer att påverka litteraturens form och innehåll är sannolikt något som vi, inom biblioteks-och informationsvetenskap, kommer att få skäl att återkomma till även i framtiden. För även om det, med den intensiva debatten i backspegeln, kan tyckas verka som att "ljudböckerna anfaller" (Holmström 2016) kan det, som kritikern och författaren Josefin Holmström påpekar "dröja ett bra tag innan vi med säkerhet vet hur ljudboken påverkat litteraturen som vi känner den." Under den tiden, gör vi som är intresserade av denna utveckling kanske bäst i att själva pröva någon av de digitala ljudbokstjänsterna och reflektera kring vad denna typ av litteraturkonsumtion gör med oss som läsare. 


\section{Referenser:}

Ahlström, K. (2018) Så har ljudböckerna förändrat berättandet och dramaturgin, Dagens Nyheter, 6 april.

Andersson, P. (2018) Ljudbokens fördel och förbannelse. Ordfronts Pelle Andersson om en bokbransch i stark förvandling, Dagens Nyheter, 16 april.

Baron, S. N. Words onscreen: The fate of reading in a digital world New York: Oxford University Press.

Berggren, H. (2018) Sanningen kräver stil och gestaltning, Dagens Nyheter, 9 april.

Bergström, Annika. \& Höglund, Lars. (2016). "E-bokens spridning saktar in" Red. Ohlsson, Oscarsson \& Solevid: Ekvilibrium, Göteborgs Universitet, SOM- institutet

Borg, A. (2013) " Lättläst, kortläst, snabbläst. Litteratur i det lilla formatet i digitaliseringens tidevarv.", Tidskrift för litteraturvetenskap, vol 43. Nr 2. S.83-95

Sarrimo. C. (2018) Varför förväntas vi som lyssnar på ljudböcker rodna. Dagens Nyheter, 9 april.

Erba, A. (2018). Kan du höra den här texten?. Dagens Nyheter, 31 Augusti

Have, Iben \& Stougard Pedersen (2016). Digital audiobooks - new media, users and experiences. New York; Routledge, Taylor \& Francis Group.

Hayles, Katherine (2012). How we think - Digital media and contemporary technogenesis, Chicago, III. : University of Chicago Press.

- "Intermediation. The pursuit of a vision" (2007) New Literary History, Volume 38, Number 1, Winter, s. 99-125

Holmström, Josefin (2016). "Ljudböckerna anfaller", Fokus, 2.12.2016.

Lenas, S. (2016) Ljudboken skapar luckor i litteraturen. Dagens Nyheter, 18 juli.

Lenas, S \& Cederskog, G. (2018) Så tycker författarna om ljudboken: "Intelligent litteratur kommer att vinna i längden, Dagens Nyheter, 23 mars.

Myndigheten för kulturanalys (2017). Kulturen i siffror 2017, Stockholm: Myndigheten för kulturanalys.

Pennlert, Julia, (2018 under publ.) "Röster om den kommersiella ljudboken i Sverige - några nedslag och exempel."

Rubery, Matthew, (2016) The untold story of the talking book, Cambridge, Massachusetts : Harvard University Press. 
Weibull, Lennart. \& Nilsson, Åsa. (2010) "Boken - var står den idag?" Red. Holmberg, S \& Weibull, L. Nordiskt Ljus, Göteborg, SOM-Institutet, Göteborgs Universitet.

Wikberg, Erik (2018) Bokförsäljningsstatstiken - första halvåret 2018 (2018)

Wikberg, Erik, (2018) Boken 2018 - marknaden, trender och analyser, (2018) Rapport från Svenska Bokhandlareföreningen och Svenska Förläggareföreningen, Stockholm.

Wilson, S. (2018) Bokvärlden vänder blad, Fenina, 19 juni.

Åberg, D. (2018) Varför ignorerar kritikerna ljudboken. Dagens Nyheter, 24 april. 